\title{
Summary.
}

I. When 6-nitro- $m$-cresol is brominated in acetic acid solution, a mixture of 4-bromo-6-nitro- $m$-cresol and 2,4-dibromo-6-nitro-m-cresol is formed. The difference in solubility of these two products in acetic acid permits of almost complete separation by filtration of the reaction mixture. 4-Bromo-6-nitro-m-cresol, which had not previously been described, has been studied and its structure established.

2. The ortho positions of the hydroxyl and nitro groups in the mononitrodibromo-m-cresol (m. p. $87^{\circ}$ ) obtained by nitration of $2,4,6$-tribromo$m$-cresol ${ }^{1}$ have been confirmed.

3. When 4 -bromo-6-nitro-m-cresol is chlorinated in the presence of iron, chlorine enters position II, that is, between methyl and hydroxyl.

4. Treatment of 2-chloro-4-bromo-6-amino- $m$-cresol with nitrous acid gives a diazo-oxide that will react with cuprous chloride to give a trihalogenated cresol.

Chicago, ini.

\section{THE ACTION OF CHLORAL, CHLORAL HYDRATE AND BROMAL ON CERTAIN ORGANIC COMPOUNDS IN THE PRES- ENCE OF ALUMINIUM CHLORIDE.}

By G. B. Franiforter aNd W. KRITCheVsky.

Received May 13, 1914.

\section{Part I.}

The following pages are devoted to a new phase of the Friedel-Crafts reaction. This unique historical reaction ${ }^{2}$ represents one of a series of chemical changes commonly classed under catalysis. Catalysis may be best defined as a chemical change, either analytic or synthetic, brought about by the influence of a substance but without that substance entering permanently into the reaction; or, as stated by Ostwald, an increase in the reaction velocity beyond the normal by some substance which does not enter the reaction.

As is well known, many of the true organic condensation processes are brought about by one of two common reactions, namely, the FriedelCrafts and the Baeyer reaction, the one acknowledged as purely catalytic, eliminating hydrochloric acid-the other, perhaps dehydrolytic, eliminating water. It will be shown in this paper that although these two reactions have been regarded as separate and distinct in their behavior ever since they were discovered by the men whose names they bear, they do, in many cases, act alike; for aluminium chloride not only plays the part of a catalyst in breaking off hydrochloric acid, but it also acts as a substitute for sulfuric acid, removing water from the reacting components.

1 J. prakt. Chem., [2] 61, 561 (1900); Am. Chem. J., 46, 426 (I9ri).

${ }^{2}$ Compt. rend., 84, I392 (1877); Ann. chim. phys., [6] 449 (1884). 
It may be of some historic interest to note that Playfair was doubtless the first to show the catalytic properties of aluminium. He found that if a piece of calico dyed in indigo be dipped in nitric acid, no change takes place; but if the nitric acid contains a mere trace of an aluminium salt, the blue color is immediately destroyed.

It was found by Friedel and Crafts that, when small quantities of anhydrous aluminium chloride were added to amyl chloride, a vigorous reaction took place, liberating hydrochloric acid, at the same time forming hydrocarbons which did not absorb bromine. The reaction seemed deep seated, but one of the compounds formed was a hydrocarbon of the general formula, $\mathrm{C}_{n} \mathrm{H}_{2 n+2}$, thus indicating that a different hydrocarbon of the same group had been formed. Finally, when the above reaction was made to take place in the presence of a hydrocarbon, a compound consisting of the hydrocarbon and the amyl radical was formed. By substituting other halides, as methyl or ethyl chlorides, homologous compounds were formed. No definite explanation was at first given. The reaction was so unusual that the discoverers seem to have been content to accept the reaction as fact and wait for more data before attempting an explanation.

In addition to the work of the authors themselves, Gustavson ${ }^{1}$ did much toward an explanation of the reaction. He showed that organic aluminium compounds of unstable nature are formed and that these compounds readily break down, liberating the condensed hydrocarbon with the reformation of aluminium chloride.

Since Friedel and Crafts' first experiments with aluminium chloride, chemists have used it in many different ways for bringing about different chemical changes. Thus, Scholl and Seer $^{2}$ showed that anhydrous aluminium chloride in many cases actually breaks off hydrogen instead of hydrochloric acid, as may be shown by the following equation:

$$
\mathrm{C}_{5} \mathrm{H}_{12}+\mathrm{Al}_{2} \mathrm{Cl}_{6}=\mathrm{C}_{5} \mathrm{H}_{10}+\mathrm{H}_{2}+\mathrm{Al}_{2} \mathrm{Cl}_{6}
$$

They did not attempt to explain this reaction, but, from organic aluminium compounds which we have had in hand, it seems quite probable that the first substance formed is an aluminium compound as indicated by the following equation:

$$
\mathrm{C}_{5} \mathrm{H}_{12}+\mathrm{Al}_{2} \mathrm{Cl}_{6}=\mathrm{C}_{5} \mathrm{H}_{11} \mathrm{Al}_{2} \mathrm{Cl}_{5}+\mathrm{HCl}
$$

Then the hydrogen ion of the acid breaks the aluminium alkyl down, liberating the hydrogen and reforming aluminium chloride according to the following equation:

$$
\begin{aligned}
& \qquad \mathrm{C}_{5} \mathrm{H}_{11} \mathrm{Al}_{2} \mathrm{Cl}_{5}+\mathrm{HCl}=\mathrm{C}_{5} \mathrm{H}_{10}+\mathrm{Al}_{2} \mathrm{Cl}_{6}+\mathrm{H}_{2} \\
& { }_{1} \text { Bull. soc. chim., 42,325 (1884);Ber., I3, } 55 \text { (1880). } \\
& { }^{2} \text { Monatsh., 33, I (1912). }
\end{aligned}
$$


Page $^{1}$ has recently shown that anhydrous aluminium chloride possesses the power of transporting chlorine to organic compounds. In a very few cases, we have suspected it of having similar properties, although the evidence at hand is not entirely conclusive.

Another reaction which is more or less closely related to those described below, is the synthesis of anthraquinone from phthalic anhydride and benzene, by means of aluminium chloride and sulfuric acid. At first glance the chloride might be regarded as a dehydrating agent. A careful examination will show, however, that the reaction brought about by aluminium chloride is not condensation at all but an addition reaction, dehydration being brought about by means of concentrated sulfuric acid, as may be shown by the following equation:

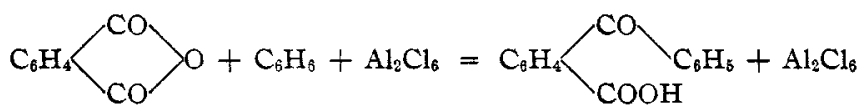

The final reaction in which a molecule of water was removed was brought about by means of sulfuric acid:

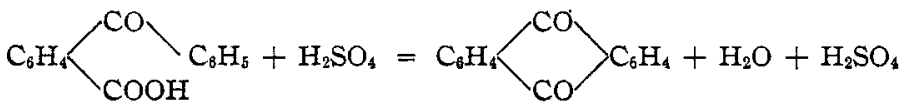

\section{Experimental Part.}

The first experiments in which it was observed that aluminium chloride had dehydrating properties were made by one of us and Poppe ${ }^{2}$ with pinene, chloral and aluminium chloride. These substances, when brought together at the ordinary room temperature undergo an extremely complex reaction, forming, as one of the condensation reactions, substances which do not contain oxygen. It was naturally inferred that in this part of the reaction, pinene and chloral must have combined through the elimination of water. Just how the reaction takes place has not yet been determined with absolute certainty. The natural inference is, however, that aluminium chloride in some part of the reaction plays the part of a dehydrating reagent. Following out the assumption that water is eliminated from pinene and chloral by aluminium chloride, the various groups of organic compounds were substituted for pinene. In each case theory became fact, for in each case the chloride acted as a plain dehydrating reagent.

Our first experiments with anisol and phenetol, chloral and aluminium chloride showed, as was suspected in our work on the terpenes, that the latter acts exactly like concentrated sulfuric acid in removing a molecule of water and forming a trihalogen condensation product. Some of this

1 Ann., 225, 196 (1884).

2 Contribution to Our Knowledge of the Terpenes, Frankforter and Poppe. Read before International Congress of Applied Chemistry, New York, I 912. 
series of compounds had been previously prepared by the Baeyer or sulfuric acid reaction. None, however, had been prepared by means of aluminium chloride. In fact, a number of these ether derivatives were prepared for the first time by the aluminium chloride method and reported by us at the Eighth International Congress of Applied Chemistry at New York, I9I2.

Experimental work soon showed that this peculiar action of aluminium, chloride is by no means confined to the phenol ethers. On the contrary it appeared to be almost as universal in its application as a dehydrating reagent as sulfuric acid. We have used it in preparing condensation products of the aliphatic, the benzene, the naphthalene and the anthracene series, not only with chloral but also with chloral hydrate and bromal.

General Method of Preparation.-In the preparation of the compounds which appear in this paper, the reactions were practically all brought about in the same manner. The two reacting components were first mixed and after cooling to zero or below, aluminium chloride was added in small portions and the whole allowed to stand for 24 to $72 \mathrm{hrs}$. in a freezing mixture. In each case the reaction seemed to have been completed within the above mentioned time limits. After the reaction had been completed, the whole mass was washed with water and distilled with steam in order to remove the unchanged reacting components. The condensation product was, in most cases, removed by extracting with ether from which it usually crystallized. Those substances which refused to crystallize from ether were invariably found to crystallize from chloroform or alcohol. In a very few cases the substance could only be obtained in a semicrystalline form, in which case the constant melting point was regarded as sufficient evidence that the substance was pure enough for analysis. In a few cases the substance had to be distilled in vacuo before it would crystallize from ether, alcohol or any other organic solvents.

Condensation of the Aliphatic Hydrocarbons, Chloral and Aluminium Chloride.-Pentane and chloral react vigorously when brought together in the presence of aluminium chloride. So extremely violent is the reaction that, even at a freezing temperature it is complex, giving as a result several substances, none of which has been obtained quite pure enough for analysis. It is evident, however, that the condensation reaction takes place eliminating a molecule of water. This and other experiments with the aliphatic compounds are under investigation.

Condensation of the Aromatic Hydrocarbons, Chloral and Aluminium Chloride.-It was found that the aromatic hydrocarbons, when treated with chloral in the presence of aluminium chloride, formed the same condensation products obtained by other condensation reagents. Thus, benzene, toluene and xylene gave their own characteristic condensation compounds according to the common equation: 
$2 \mathrm{RH}+\mathrm{OCH}-\mathrm{CCl}_{3}+\mathrm{Al}_{2} \mathrm{Cl}_{6}=\mathrm{R}_{2} \mathrm{CH}-\mathrm{CCl}_{3}+\mathrm{H}_{2} \mathrm{O}+\mathrm{Al}_{2} \mathrm{Cl}_{6}$, when $R$ represents the phenyl, toluyl and the xylyl groups.

It should be stated here that benzene, chloral and aluminium chloride have recently been studied, but different investigators have obtained entirely different results. Thus, Combes, ${ }^{1}$ by treating Iooo $\mathrm{g}$. of benzene with $200 \mathrm{~g}$. of chloral and $40 \mathrm{~g}$. of aluminium chloride, obtained an extremely complex reaction. No less than four different substances were isolated:

I. Diphenylchloral hydrochloride, $\left(\mathrm{C}_{6} \mathrm{H}_{5}\right)_{2} \mathrm{CH}-\mathrm{CCl}_{3} \mathrm{HCl}$ (liquid with an aromatic odor).

2. Diphenyldichloroethane, $\left(\mathrm{C}_{6} \mathrm{H}_{5}\right)_{2} \mathrm{CHCHCl}_{2}$, solid, m. p. $74^{\circ}$.

3. Compound of unknown composition, $\mathrm{C}_{22} \mathrm{H}_{17} \mathrm{Cl}$, solid, m. p. $83^{\circ}$.

4. Tetraphenylethane, $\left(\mathrm{C}_{6} \mathrm{H}_{5}\right)_{2} \mathrm{CH}-\mathrm{CH}\left(\mathrm{C}_{6} \mathrm{H}_{5}\right)_{2}$.

$\mathrm{Biltz}^{2}$ obtained the following results by treating benzene and chloral with aluminium chloride:

I. Tetraphenylethane, $\left(\mathrm{C}_{8} \mathrm{H}_{5}\right)_{2} \mathrm{CH}-\mathrm{CH}\left(\mathrm{C}_{6} \mathrm{H}_{5}\right)_{2}$, solid, m. p. $207^{\circ}$.

2. Diphenyldichloroethylene, $\left(\mathrm{C}_{6} \mathrm{H}_{5}\right)_{2} \mathrm{C}=\mathrm{CCl}_{2}$, solid, m. p. $80^{\circ}$.

3. Triphenylvinyl alcohol, $\left(\mathrm{C}_{6} \mathrm{H}_{5}\right)_{2} \mathrm{C}=\mathrm{C}(\mathrm{OH}) \mathrm{C}_{6} \mathrm{H}_{5}$, solid, m. p. $136^{\circ}$, and a substance of unknown composition with a melting point of $233^{\circ}$.

Böeseken $^{3}$ very recently (since an abstract of this paper was read at the 8th International Congress) repeated the work of Combes and Biltz. He explained the reaction by assuming that diphenylmethane and chloroform are formed. This work was not absolutely proven, as he himself states.

Of equal interest, along this line, is the work of Dienesmann, ${ }^{4}$ who, upon treating I000 $\mathrm{g}$. of benzene with $200 \mathrm{~g}$. of chloral and $40 \mathrm{~g}$. of aluminium chloride in the cold, obtained a reaction which he expressed as follows:

$$
\mathrm{C}_{6} \mathrm{H}_{6}+\mathrm{OCH}-\mathrm{CCl}_{3}=\mathrm{C}_{6} \mathrm{H}_{5}(\mathrm{OH}) \mathrm{CH}-\mathrm{CCl}_{3}
$$

In other words, Dienesmann obtained the aldol reaction in which a secondary alcohol is formed. It is interesting to note that this compound is doubtless the same which Jotsitch ${ }^{5}$ obtained by means of the Grignard reaction.

Dienesmann's reaction is of special interest because he worked under conditions somewhat similar to those under which we have worked. The results obtained, however, were entirely different. This is rather strange, because the only difference in the experimental work seems to be the fact that he took a large excess of benzene while we took exactly two

1 Bull., 45, 226 (1886).

${ }^{2}$ Ber., 26, 1952 (1893).

${ }^{3}$ Chem. Zentr., 1912, I, 897.

4 Compt. rend., I4I, 201 (1905).

${ }^{6} J$. Russ. Phys. Chem. Soc, 34, 96 (1902). 
molecules. He kept the reacting substances cool (he does not state how cool) while we kept the temperature down to zero or below. In our experiments the aldol reaction did not take place and the secondary alcohol was therefore not formed. On the contrary, we obtained a simple condensation reaction.

A glance at the Dienesmann reaction will show that it represents what one would expect from either the Friedel-Crafts or of the Grignard reaction. It is at least interesting to note that we have obtained quite different results from those obtained by Dienesmann by simply changing the conditions under which the reaction takes place, namely, changing the proportions of the reacting components and the temperature. From the important work of Dienesmann and from the experiments which follow, it is evident that aluminium chloride, under one set of conditions, acts as a simple catalyst, while under different conditions it plays the part of a dehydrating reagent.

The following table will show the relationship between the Grignard, the Friedel-Crafts and the Baeyer reactions as compared with the one given in this paper.

$$
\begin{gathered}
\text { Grignard. } \\
\mathrm{C}_{6} \mathrm{H}_{6}+\mathrm{Mg}+\mathrm{I}_{2}+\mathrm{OCH}-\mathrm{CCl}_{3}=\mathrm{C}_{6} \mathrm{H}_{6} \mathrm{CH}(\mathrm{OH}) \mathrm{CCl}_{3}+\mathrm{MgI}_{2} \\
\quad \text { Friedel-Crafts. } \\
\mathrm{C}_{6} \mathrm{H}_{6}+\mathrm{OCH}-\mathrm{CCl}_{3}+\mathrm{Al}_{2} \mathrm{Cl}_{6}=\mathrm{C}_{6} \mathrm{H}_{5}-\mathrm{CH}(\mathrm{OH}) \mathrm{CCl}_{3}+\mathrm{Al}_{2} \mathrm{Cl}_{6} \\
\quad \text { Baeyer. } \\
{ }_{2} \mathrm{C}_{6} \mathrm{H}_{6}+\mathrm{OCH}-\mathrm{CCl}_{3}+\mathrm{H}_{2} \mathrm{SO}_{4}=\left(\mathrm{C}_{6} \mathrm{H}_{5}\right)_{2} \mathrm{CH}-\mathrm{CCl}_{8}+\mathrm{H}_{2} \mathrm{O}+\mathrm{H}_{2} \mathrm{SO}_{4} \\
\quad \text { Frankforter--Kritchevsky. } \\
{ }_{2} \mathrm{C}_{8} \mathrm{H}_{6}+\mathrm{OCH}-\mathrm{CCl}_{3}+\mathrm{Al}_{2} \mathrm{Cl}_{6}=\left(\mathrm{C}_{6} \mathrm{H}_{5}\right) \mathrm{CH}-\mathrm{CCl}_{3}+\mathrm{H}_{2} \mathrm{O}+\mathrm{Al}_{2} \mathrm{Cl}_{6}
\end{gathered}
$$

Benzene, Chloralhydrate and Aluminium Chloride.-Benzene reacts with chloralhydrate in the presence of aluminium chloride almost as vigorously as does pentane, so that it was also necessary to bring the reaction about at a low temperature. The first experiment was carried out as follows: $50 \mathrm{~g}$. of pure benzene $(2 \mathrm{~mol}), 57 \mathrm{~g}$. of chloralhydrate $\left(\mathrm{r}^{1} / 4 \mathrm{~mol}\right)$ were cooled down to zero, and with constant shaking ro g. of aluminium chloride added piecemeal. As in the case of pentane, hydrochloric acid was liberated and the whole changed to a light blue color. After allowing it to stand for $48 \mathrm{hrs}$. the whole mass was poured into water and distilled with steam. The unchanged benzene passed over with the steam. It was found that only a comparatively small quantity of benzene had been acted upon by the chloralhydrate as most of the benzene was recovered and the residue appeared to be unchanged chloralhydrate and aluminium chloride. The experiment was repeated, using the same amounts of benzene and chloralhydrate but increasing the aluminium chloride to one-half molecule. Again a considerable quantity of the benzene remained unchanged. There was left in the flask, however, in addition to the chloralhydrate and 
aluminium chloride a thick black oil which did not appear in the first experiment, but the amount was too small for further investigation.

The above experiments were again repeated, using a large amount of aluminium chloride in order to show whether or not the quantity of chloride in any way changed the reaction. The same amounts of benzene and chloralhydrate were taken but the aluminium chloride was increased to $175 \mathrm{~g}$., and added piecemeal as before, to the cooled benzene. During the adding of the chloride, which extended over four hours, the temperature was not allowed to rise above zero. Again, a large amount of hydrochloric acid passed off and the whole mass changed, taking on a deep blue color. After all the chloride had been added the whole mass was allowed to stand $48 \mathrm{hrs}$. in a refrigerator. During this time more hydrochloric acid was liberated. Ice-water was then added and the mixture allowed to stand for some time. The whole was finally distilled with steam. The steam distillate contained only a small amount of benzene and a small quantity of an oil which had a higher boiling point than benzene, thus indicating that the increase of aluminium chloride had increased the reaction. The residue in the flask, consisting of a thick, dark oil, was washed with water and extracted with ether. The ether solution had a deep greenish fluorescence. The mixture, containing both the ether and aqueous solutions, was washed with sodium hydroxide and finally with dilute hydrochloric acid. The ether solution was then separated from the aqueous part, dried over calcium chloride and the ether allowed to evaporate. The residue left, after evaporating off the ether, was a black, oily liquid. An examination indicated that it was a mixture of several substances. In order to separate them the oil was subjected to fractional distillation in vacuo. The first part of the distillate passed over almost colorless at $180^{\circ}$ and $55 \mathrm{~mm}$. pressure. It had a distinctly aromatic odor. It was soluble in all the common organic solvents, but refused to crystallize from any of them. It was carefully studied and analyzed. Both physical properties and analysis correspond exactly with the compound, $\mathrm{C}_{6} \mathrm{H}_{5} \mathrm{CCl}_{2}-\mathrm{CHO} . \mathrm{HCl}$, which Combes ${ }^{1}$ prepared. In this part of the reaction, therefore, aluminium chloride apparently played the part of a catalyst as indicated by the following equation:

$$
\mathrm{C}_{6} \mathrm{H}_{6}+\mathrm{CCl}_{3} \mathrm{CHO}+\mathrm{Al}_{2} \mathrm{Cl}_{6}=\mathrm{C}_{6} \mathrm{H}_{5}-\mathrm{CCl}_{2} \mathrm{CHO} . \mathrm{HCl}+\mathrm{Al}_{2} \mathrm{Cl}_{6} \text {. }
$$

Fractional distillation was continued when the second part distilled over between $220^{\circ}$ and $245^{\circ}$. Most of it solidified in the condenser in the form of fine crystals. It was removed and recrystallized from alcohol and ether. After crystallization, it appeared as well-formed, transparent crystals with a melting point of $63-64^{\circ}$. It corresponds exactly with diphenyltrichlorethane, $\left(\mathrm{C}_{6} \mathrm{H}_{5}\right)_{2} \mathrm{CH}-\mathrm{CCl}_{3}$, which Baeyer ${ }^{2}$ obtained by the

I Bull., 45, 226 (I886).

2 Ber., 5, I098 (I873). 
condensation of benzene with chloral by means of concentrated sulfuric acid. Analysis also confirmed the reaction.

It is evident from the results obtained that aluminium chloride played a double role. In the formation of the above-mentioned hydrochloride, its action is not unlike the Friedel-Crafts catalysis. In the formation of the diphenyl compound, however, it acts exactly like concentrated sulfuric acid.

Toluene, Chloral and Aluminium Chloride.-It was found that chloral reacted with toluene in the presence of aluminium chloride, forming a condensation product similar to its reaction given above with benzene. $300 \mathrm{~g}$. of toluene were treated with $300 \mathrm{~g}$. of chloral and $175 \mathrm{~g}$. of aluminium chloride under the same conditions mentioned under benzene, and finally distilled in vacuo. An oil passed over at $170-180^{\circ}$ under $30 \mathrm{~mm}$. pressure with some hydrochloric acid. The oil was dissolved in a mixture of alcohol and ether and allowed to stand, when well-formed, transparent crystals separated out. Recrystallized, it had a m. p. of $88^{\circ}$.

Analysis gave the following: C, 61.20, $\mathrm{H}, 4.82$, and $\mathrm{Cl} .33 .5$.

These analyses, with the physical properties of the substance, leave no doubt that it is p-ditoluyltrichloroethane, $\left(\mathrm{CH}_{3}-\mathrm{C}_{6} \mathrm{H}_{4}\right)_{2} \mathrm{CHCCl}_{3}$, prepared by Fischer from toluene, chloral and concentrated sulfuric acid.

p-Toluyldichloroacetaldehydehydrochloride.-During the process of distillation in preparing the ditoluene compound, an oil passed over in addition to the crystals already described. It was carefully studied and found to be a homolog of the Combes benzene derivative. It therefore has the following formula:

$$
\mathrm{CH}_{3} \cdot \mathrm{C}_{6} \mathrm{H}_{4}-\mathrm{CCl}_{2} \mathrm{CHO} . \mathrm{HCl} \text {. }
$$

We are unable to satisfactorily explain the structural formula of this peculiar compound, the benzene derivative of which was prepared by Combes, ${ }^{1}$ who represents the one which he isolated by the above general formula. We hope in the near future to carefully study the structure of these peculiar compounds.

Xylene, Chloral and Aluminium Chloride.-Following the same process used in the preparation of the benzene and toluene condensation products, xylene was treated with chloral in the presence of aluminium chloride. One hundred grams of xylene, $98 \mathrm{~g}$. chloral and $80 \mathrm{~g}$. of aluminium chloride were brought together as in previous experiments, and finally distilled in vacuo. A perfectly clear oil with an aromatic odor distilled over between 190 and $220^{\circ}$ at $25 \mathrm{~mm}$. pressure. It readily changed over to crystals, which, after recrystallization from alcohol, had a melting point of $106^{\circ}$. A careful examination, including analyses, showed that the substance was identical with $m$-dixylyltrichloroethane prepared by Elbs from xylene chloral and sulfuric acid. In this case, however, only one substance, the 
one mentioned above, was formed. Hence, aluminium chloride did not play the role of the Friedel-Crafts catalytic agent.

Cymene, Chloral and Aluminium Chloride.-Cymene was also treated in the usual way with chloral and aluminium chloride, but was found to react quite differently from any of the other hydrocarbons, doubtless owing to its peculiar relationship to the terpenes. $50 \mathrm{~g}$. of cymene $(2 \mathrm{~mol})$, $30.8 \mathrm{~g}$. of chloral and $25 \mathrm{~g}$. of aluminium chloride were brought together under exactly the same conditions as in the other hydrocarbons, and finally subjected to fractional distillation under diminished pressure.

The first distillate which passed over was a thick liquid at $220^{\circ}$ and at $33 \mathrm{~mm}$. pressure. The product, before subjecting to distillation, was doubtless an organic aluminium compound, which was found to be soluble in both alcohol and ether but which refused to crystallize from either. The distillate contained no aluminium and only a trace of chloral. It proved to be an unsaturated compound absorbing bromine with great avidity. None of the derivatives formed, however, could be obtained in pure enough form for analysis.

\section{Condensation of Alcohols, Phenols and Phenol Ethers with Chloral, Chloral Hydrate and Bromal by means of Aluminium Chloride.}

Alcohol, Chloral and Aluminium Chloride.-When alcohol and chloral are brought together the temperature rises, and as is already known, a liquid is formed which may be easily identified as trichloroacetal. As we were especially interested in the chloral reactions which take place in the presence of aluminium chloride, the following experiment was tried: Seventy grams of absolute alcohol were placed in a flask and cooled down to below zero by ice-water and ammonium nitrate; roo g. of chloral and $25 \mathrm{~g}$. of aluminium chloride were quickly added and vigorously shaken. A turbid mass indicated that the reaction which had taken place was the same as that which takes place with alcohol and chloral alone. However, when the chloride was added under ordinary conditions, the temperature rose and hydrochloric acid was liberated. By adding $70 \mathrm{~g}$. more of the chloride and allowing to stand for 48 hours, the reaction appeared to have entirely changed. The mass thus treated was poured into ice-water and the insoluble part and extracted with ether. The extract was dried with calcium chloride, the ether evaporated off and the residue subjected to fractional distillation. A small part passed over below the boiling point of ether. It had a sharp pungent odor. The second distillate was easily recognized as common acetaldehyde. Then some ether passed over and, at about $100^{\circ}$, chloral hydrate. After the above substances had been removed, the temperature rapidly rose to $170-200^{\circ}$, when a distinctly aromatic oil distilled over. After redistillation, it boiled at $197^{\circ}$. It had the general physical properties of trichloroacetal. 
The appreciable quantity of acetaldehyde would indicate that chloral acts as an oxidizing agent.

We were somewhat surprised to find that the trichloroacetal formed in this reaction did not possess all of the properties generally ascribed to it. It may be of interest here to note that an isomer of trichloroacetal was obtained by Liebens. ${ }^{1}$ It is not impossible that the above substance is the one which Liebens describes.

Benzyl Alcohol, Chloral and Aluminium Chloride.-The reaction between benzyl alcohol and chloral is less energetic than between common alcohol and chloral; so much so, in fact, that the reaction may be brought about at the ordinary room temperature. The reaction was brought about as follows: $75 \mathrm{~g}$. of benzyl alcohol, $50 \mathrm{~g}$. of chloral and 45 of aluminium chloride were brought together at room temperature. The action began immediately. Hydrochloric acid was liberated and the whole mass changed to a chocolate-brown color. The mass was allowed to stand for 24 hours and then treated with water in order to remove the unchanged chloral and the aluminium chloride. The residue was then distilled with steam. That which passed over was extracted with ether, the latter removed and the extracted substance subjected to distillation. Most of it passed over at $I 73^{\circ}$ and was identified as benzaldehyde. It would appear, therefore, that chloral in this particular case acts as an oxidizing reagent, changing the benzyl alcohol to the aldehyde.

The mass which remained in the flask was extracted with ether, the ethereal solution washed with water, dried, and the ether removed by evaporation; the residue was then subjected to distillation. It distilled over at from $150-300^{\circ}$, thus indicating by the variable boiling point that the substance is a mixture of two or more compounds. It is a liquid at the ordinary temperature. It proved to be organic, but it contained a large amount of chlorine. It also gave the aldehyde reaction. In order to obtain it in a pure enough form for analysis it was again subjected to distillation. Unfortunately, we were unable to obtain a substance with a constant boiling point. As this substance is of considerable interest it has been set aside for further investigation as soon as time will permit.

Phenol, Chloral and Aluminium Chloride.-Forty-nine grams of phenol, $40 \mathrm{~g}$. chloral and $35 \mathrm{~g}$. of aluminium chloride were brought together under conditions already mentioned, and allowed to stand for two days at freezing temperature. Hydrochloric acid gas was liberated in large quantities. The whole mass was then treated with water and finally distilled with steam. That which was left in the distilling flask was a reddish brown, waxy mass with a distinct phenol odor. The waxy substance was thoroughly washed with water. The odor of phenol slowly disappeared and the substance changed to a semisolid. The substance thus purified

1 Ann., 104, II4 (1857). 
was quite soluble in alcohol and ether, from which it refused to crystallize. Benzene dissolved a part readily, while a part was quite insoluble. The insoluble part appeared as a fine crystalline powder. The substance was filtered off, washed with benzene, was finally recrystallized from acetic acid, in which it is very soluble. Thus purified, the substance melted at $212^{\circ}$ and analyses gave numbers which correspond to $p$-dihydroxydiphenyltrichloroethane, which was obtained by ter Meer $^{1}$ by treating chloral and phenol with concentrated sulfuric acid. To prove the constitution, however, the compound was converted into an acetyl derivative which had a m. p. of $138^{\circ}$-the same which ter Meer found for the substance obtained from sulfuric acid. The part which was soluble in benzene is a dark brown, resinous powder which contains chlorine. This substance is new and is now being studied.

Diresorcyldichloroethylene.-Resorcin and chloral, when brought together, do not combine with each other, but the chloral is absorbed by the solid resorcin forming a solid mass. The substances were therefore first dissolved in carbon disulfide before adding the chloride. Twenty-five grams of resorcin and $20 \mathrm{~g}$. of chloral were dissolved in $200 \mathrm{~g}$. of carbon disulfide and $20 \mathrm{~g}$. of aluminium chloride cautiously added. The condensation product was purified by treating with water and steam and finally from alcohol and acetic acid. The substance thus purified was a brown powder with an unpleasant odor. It contained a considerable quantity of aluminium. It attacked the eyes vigorously. As results were not very satisfactory the three substances were brought together in different proportions. Twenty grams of resorcin, $40 \mathrm{~g}$. of chloral and $15 \mathrm{~g}$. of aluminium chloride were brought together as indicated above. After thoroughly purifying, the substance appeared as a light brown powder without odor. It contained some inorganic matter, presumably aluminium chloride. It was purified by dissolving in alcohol and reprecipitated with dilute hydrochloric acid. By repeating this process several times the powder was obtained practically free from aluminium.

Analysis gave: $\mathrm{C}=53.63, \mathrm{H}=3.3 \mathrm{O}, \mathrm{Cl}=22.77$. Calc. for $\mathrm{CCl}_{2}\left(\mathrm{C}_{2} \mathrm{H}_{3}(\mathrm{OH})_{2}\right)_{2}$ : $\mathrm{C}=53.83, \mathrm{H}=3.21, \mathrm{Cl}=22.44$.

Tetraacetyldiresorcyldichloroethylene.-In order to determine the number of hydroxyl groups in the above resorcyl derivative it was treated with acetic anhydride and the substance thus formed purified and analyzed. Five grams of the resorcyl compound, $5 \mathrm{~g}$. of dry sodium acetate and 25 g. of acetic anhydride were heated to boiling for three hours. The excess of anhydride was changed to the ester with alcohol and ester distilled off. The light brown powder was left, which, on examination, appeared to be the pure acetic ester.

Analysis gave: $\mathrm{Cl}=14.70$. Calc.: $\mathrm{Cl}=14.57$.

${ }^{1}$ Ber., 7, I 200 (I874). 
Anisol Chloral and Aluminium Chloride.-Dianisyltrichloroethane was prepared in the following manner: $100 \mathrm{~g}$. of anisol ( $2 \mathrm{~mol}), 80 \mathrm{~g}$. of chloral $\left(\mathrm{I}^{1} / 2 \mathrm{~mol}\right)$ were brought together and cooled to $0^{\circ}$. Twelve grams of aluminium chloride were added in small portions and with frequent shaking. The mass became thick and changed to a dark green color. It was kept at a freezing temperature for 24 hrs. After the excess of chloral and aluminium chloride had been removed by means of warm water, the substance was purified, first by steam distillation and finally by crystallization from hot alcohol. After recrystallizing several times the substance appeared as thick, shiny, transparent crystals. They were soluble in nearly all of the common organic solvents and had a melting point of $78^{\circ}$.

Analyses checked for the formula, $\left(\mathrm{CH}_{3} \mathrm{OC}_{6} \mathrm{H}_{4}\right)_{2}=\mathrm{CHCCl}_{3}$.

Elbs is supposed to have prepared this substance by condensation of anisol and chloral hydrate by means of concentrated sulfuric acid. The Elbs substance, appeared at first to be a different compound from the one given above, inasmuch as he gave the m. p. as $92^{\circ}$. In order to determine whether or not the two substances are really the same, Elbs' experiment was repeated. As a result erystals were obtained which were identical with those obtained with aluminium chloride. The crystals did not have the m. p. $92^{\circ}$; as given by Elbs, but $78^{\circ}$, the same as the compound obtained with aluminium chloride.

In order to study the constitution of dianisyltrichloroethane more fully, it was reduced by means of zinc. Ten grams of the compound were placed in a flask connected with a reflux condenser with roo cc. of alcohol. Ten grams of zinc dust, together with strong alcoholic ammonia, were added and the whole mass heated on a water bath for sixteen hrs. The insoluble substance was then filtered off and the filtrate allowed to stand when fine needle-shaped crystals separated out with a melting point of $212^{\circ}$, the same that $\mathrm{Kopp}^{1}$ and Weichell ${ }^{2}$ obtained for $p$-dimethoxystilbene.

Dianisyldichloroethylene.-This substance was obtained by treating dianisyltrichloroethane prepared from anisol, chloral and aluminium chloride with alcoholic potash. The experiment was carried out as follows: $15 \mathrm{~g}$. of the anisyl compound were placed in a flask and heated with alcoholic potash on a water bath connected with a reflux condenser for 12 hours. At the end of that time the alcohol was evaporated off and the inorganic substance removed by warm water in a separatory funnel. The dianisyldichloroethylene was then dried and recrystallized from hot alcohol. The m. p. was rog ${ }^{\circ}$.

Analysis gave the following: $\mathrm{Cl}=22.58$. Calc., 22.72.

1 Ber, 25, 603 (1892).

2 Ann., 279, 341 (1894) 
Octonitrodianisyltrichloroethane.-The octonitro compound was easily prepared by treating the dianisyltrichloroethane with fuming nitric acid. Five grams of dianisyltrichloroethane were brought in contact with $5^{\circ}$ cc. of fuming nitric acid after first being cooled down to $0^{\circ}$. The acid was added slowly and the whole allowed to stand over night. The whole mass was then poured into water when the nitro compound separated out. It was purified by crystallizing from alcohol. The substance thus obtained was a beautiful light yellow, felt-like mass of crystals. The m. p. was $173^{\circ}$.

Analysis gave the following: $N=15.89$. Calc., 15.95 .

Phenetol, Chloral and Aluminium Chloride.-Chloral reacts with phenetol in the presence of aluminium chloride, forming analogous compounds to those already described with anisol.

Diphenetyltrichloroethane.-Fifty grams of phenetol, 50 of chloral and Io of aluminium chloride were treated according to the general method already described. After the reaction was completed the compound was removed, excess of the reagents removed by means of water and finally recrystallized. The substance obtained proved to be colorless, hexagonal crystals with a sharp m. p. of $105^{\circ}$.

Analysis of the dried substance gave the following:

Found: $\mathrm{C}=57.4,57.55 ; \mathrm{H}=5.33,4.60 ; \mathrm{Cl}=28.59,28.44$. Calc. $\mathrm{C}=57.95$; $\mathrm{H}=5.09 ; \mathrm{Cl}=28.42$.

As the substance proved to be of unusual interest, we undertook to prepare it by using concentrated sulfuric acid, assuming that we should find, in this case, exactly what we found in the case of anisol, that the same identical substance is formed whether the reaction is brought about with aluminium chloride or concentrated sulfuric acid as a condensation reagent. We obtained with sulfuric acid beautiful transparent crystals which, after crystallizing from alcohol, melted at $104^{\circ}$, the same as the compound prepared from aluminium chloride.

Diphenetyldichloroethylene.-This compound may be easily prepared by heating diphenetyltrichloroethane with alcoholic potash. The dichloro compound was purified from hot alcohol. It crystallizes in fine needles and melts at $97^{\circ}$. The crystals are soluble in all the common organic solvents.

$$
\text { Analysis gave the following: } \mathrm{Cl}=20.96 . \quad \text { Calc.: } \mathrm{Cl}=20.84 \text {. }
$$

p-Diethoxystilben.-This compound was prepared by reduction of the diphenetyldichloroethylene with zinc dust and alcohol and ammonia. The compound crystallizes in fine needles. It is moderately soluble in benzene but with difficulty in all other organic solvents; m. p. $207^{\circ}$. It is identical with the compound prepared from diphenetyldichloroethylene which Wiechel prepared by an entirely different method.

Octonitrodiphenetyltrichloroethane.-Five grams of diphenetyltrichloro- 
ethane were treated with $60 \mathrm{cc}$. of fuming nitric acid at freezing temperature for $16 \mathrm{hrs}$., at which time the reaction seemed to be complete. The mass was then poured into water, the precipitation removed by filtration, washed and recrystallized from hot alcohol. The substance consisted of fine yellowish needles which melt at $137^{\circ}$.

Found: $\mathrm{C}=29.42, \mathrm{H}=1.65, \mathrm{~N}=15.86$. Calc.: $\mathrm{C}=29.47, \mathrm{H}=1.50, \mathrm{~N}=$ 15.28.

Diphenetyltribromoethane.-Fifty grams of phenetol $(2 \mathrm{~mol})$ and $57 \mathrm{~g}$. (I mol) of bromal were brought together in a liter flask and cooled down to $0^{\circ}$. Ten grams of aluminium chloride were slowly added and the mixture vigorously shaken after the addition of each portion of chloride. It changed to a dark green syrupy liquid. After standing $24 \mathrm{hrs}$. in icewater the whole mass was purified by washing with warm water and finally with steam. The partially purified mass was then crystallized out of hot alcohol in yellowish crystals with a m. p. of $112^{\circ}$.

Analysis of the dried substance gave the following:

Found: $\mathrm{C}=42.89, \mathrm{H}=3.81, \mathrm{Br}=47.41$. Calc.: $\mathrm{C}=42.60, \mathrm{H}=3.75, \mathrm{Br}=$ 47.33 .

Octonitrodiphenetyltribromoethane.-Eight grams of diphenetyltribromoethane were cooled down to $0^{\circ}$ and $60 \mathrm{cc}$. of fuming nitric acid very slowly added. After standing in the freezing mixture for $20 \mathrm{hrs}$., the whole mass was poured into ice-water, the precipitate removed, washed and crystallized from hot alcohol as yellow crystals, with a sharp melting point of $153^{\circ}$. The substance proved to be analogous in every way to the octonitrodiphenetyltrichloroethane.

$$
\text { Found: } \mathrm{N}=13.08 \text {. Calc. } \mathrm{N}=12.92 \text {. }
$$

As the above-mentioned nitro compounds were easily obtained in such remarkably pure form, they were at first supposed to be analogous with those prepared, studied and analyzed by Elbs. ${ }^{1}$ A careful examination shows, however, that they are entirely different from those described by Elbs. We were somewhat surprised to find that nitric acid, like hydrochloric, does not hydrolyze the ester so along as the temperature is kept near $o^{\circ}$. On the contrary, strong nitric acid gave almost quantitative nitro products, both with the chloride and bromide of phenetol.

Aluminium bromide was tried with phenetol and bromal. We were surprised to find that no reaction took place in the presence of the bromide, although a vigorous reaction took place when aluminium chloride was substituted for the bromide. Aluminium bromide, therefore, does not act as a catalyst in this case, either in the ordinary sense of the term, breaking off hydrobromic acid, or as a condensation reagent.

Phenylether Chloral and Aluminium Chloride.-As has already been shown, the mixed aromatic-aliphatic ethers are readily condensed with

1 J. prakt. Chem., 47, 62 (1893). 
chloral in the presence of aluminium chloride, but the phenols themselves are not acted upon at all in the cold, and slowly when warmed. It was therefore of some little importance to determine whether phenylether, or diphenyloxide, really possessed the same properties as the mixed ethers to which anisol and phenetol belong. Experiments were carried out in a similar manner to those with mixed ethers, using the following proportions: $34 \mathrm{~g}$. ( $\mathrm{I} \mathrm{mol}$ ) of the ether, $30 \mathrm{~g}$. ( $\mathrm{x} \mathrm{mol}$ ) of chloral and 30 g. $\left(\mathrm{I}^{1 / 4} \mathrm{~mol}\right)$ aluminium chloride. After allowing to stand for some time, the whole was treated with water and finally distilled with steam. The residue was extracted with ether. A part only was found to be soluble. The soluble substance, after ether had been removed, was a thick liquid which finally appeared as a yellowish resin. It contained aluminium and chlorine. It did not give the aldehyde reaction. Owing to the readiness with which it decomposed, it was not obtained in pure enough form for analysis.

The part which proved to be insoluble in ether was treated with benzene. A part dissolved. The benzene soluble part, after evaporating the benzene, appeared as a yellowish amorphous powder which likewise contained aluminium. Analyses of the substance were not satisfactory, probably on account of the fact that the powder could not be obtained in a perfectly pure form. The above experiment was repeated, using different proportions of substances, but each time with the same results.

\section{Condensation of Ketones with Chloral Hydrate by means of Aluminium Chloride.}

Acetophenone, Chloralhydrate and Aluminium Chloride.-Chloralhydrate combines with acetophenone by means of aluminium chloride even in the cold. The substance formed seems to be complex, containing a small quantity of aluminium which could not be removed. Best results were obtained by using $25 \mathrm{~g}$. ( $2 \mathrm{~mol}$ ) of acetophenone, I $6 \mathrm{~g}$. ( $\mathrm{I} \mathrm{mol}$ ) of chloralhydrate, with $15 \mathrm{~g}$. of aluminium chloride, and warming under the same conditions as indicated in previous experiments. The product obtained was a thick, yellowish oil which finally changed to a solid, resinous mass. It proved to be soluble in all the common solvents. Vacuum distillation gave a distillate at $170^{\circ}$ and $40 \mathrm{~mm}$. It appeared to be the result of decomposition.

Benzophenone, Chloralhydrate and Aluminium Chloride.-While chloral combines readily with acetophenone, it apparently does not combine at all with benzophenone, for after treating with chloral in the presence of aluminium chloride, no reaction took place, as is shown by complete recovery of the original ingredients.

Condensation of Acids with Chloral and Aluminium Chloride.-Chloralaluminium-monochloroacetate, $\mathrm{Al}_{2} \mathrm{Cl}\left(\mathrm{OOCCH}_{3}\right)_{5} \mathrm{CCl}_{3} \mathrm{CHO}$. Contrary to 
expectations chloral combines with acetic acid or other monobasic acids. The first experiment was as follows: $20 \mathrm{~g}$. of acetic acid, $25 \mathrm{~g}$. of chloral and $20 \mathrm{~g}$. of aluminium chloride were brought together at ordinary room temperature. A reaction began immediately and the aluminium chloride passed into solution with liberation of hydrochloric acid. At the same time a yellow, pasty mass was formed. This yellow paste was first treated with water, the whole mass dissolved, and on evaporating the yellowish solid substance was again obtained. An attempt was made to distil it in vacuo, but it decomposed even at $15 \mathrm{~mm}$. pressure. The experiment was therefore repeated, but instead of treating with water dry ether was used. The greater part proved to be insoluble. The impurities, however, were insoluble. Ether was used, therefore, in removing the impurities. After treating several times with dry ether the residue was dried in the vacuum desiccator. The substance thus purified proved to be insoluble in most of the organic compounds. It dissolved with difficulty, however, in absolute alcohol; it was insoluble in cold water but quite soluble in hot.

The compound possesses a distinct odor of chloral together with a distinct aromatic odor. It is a light yellow powder which decomposes before reaching the melting point. It readily burns on platinum foil, leaving aluminium oxide. The salt, after repeated washings with dry ether, was subjected to analysis with the following results:

Found: $\mathrm{Cl}=26.44$ and $26,39, \mathrm{Al}_{2} \mathrm{O}_{3}=10.32 . \quad \mathrm{Calc} .: \mathrm{Cl}=26.55, \mathrm{Al}=10.17$.

In order to distinguish between the chlorine in the group $\mathrm{Al}_{2} \mathrm{Cl}\left(\mathrm{OOCCH}_{3}\right)_{5}$ and the chlorine in the chloral the whole was treated with nitric acid and silver nitrate, with the hope that the silver nitrate would remove the chlorine from the aluminium group only. We found, on the contrary, that the chlorine in the chloral was also removed, and other methods of separation were tried.

It was found that when the powder was treated with cold absolute alcohol the chloral was completely removed while the aluminium radicat remained undissolved.

The salt was therefore treated with absolute alcohol until all of the chloral had been removed. The residue was then treated with water until all of the aluminium had been removed. The residue when tested showed the presence of chlorine while the alcohol was found to contain all of the chloral.

Determinations of chlorine in the alcoholic and aqueous solutions showed that just three-quarters of the total amount of chlorine in the substance had been extracted by the alcohol, the balance being left in the aqueous solution. These results indicate that a quantitative separation of the chloral from the aluminium chloroacetate had been made and that the above formula is therefore correct. 
Very recently Böeseken and Cluwen ${ }^{1}$ succeeded in isolating a compound formed from aluminium chloride and acetic anhydride, the reaction which they represent as follows:

$$
2\left(\mathrm{CH}_{3} \mathrm{CO}\right)_{2} \mathrm{O}+\mathrm{AlCl}_{3}=\mathrm{AlCl}\left(\mathrm{OCOCH}_{3}\right)_{2}+{ }_{2} \mathrm{CH}_{3} \mathrm{COCl} \text {. }
$$

They also found that the above compound formed a double salt with ethylether, $\left(\mathrm{CH}_{3} \mathrm{CH}_{2}\right)_{2} \mathrm{O} .2 \mathrm{AlCl}\left(\mathrm{OCOCH}_{3}\right)_{2}$.

Benzoic Acid, Chloral and Aluminium Chloride.-Benzoic acid does not react with chloral. Several experiments were tried with the acid in solution and finally with chloral itself in the presence of aluminium chloride, but with little or no change. The solution turned brown, but on treating with water, pure benzoic acid was recovered.

Pyridine, Chloral and Aluminium Chloride.-When chloral, pyridine and aluminium chloride are brought together a vigorous reaction takes place, and there is formed a substance which has the appearance of common butter. It was found to be insoluble in practically all of the organic solvents. As this substance could not be obtained in pure form the experiment was modified by bringing the chloral and aluminium chloride together and afterward adding the pyridine. The mass became hot from the heat of reaction and a white vapor was given off, but no hydrochloric acid was liberated.

After the whole mass had been treated with water a bright yellow powder was separated out which proved to be insoluble in practically all the solvents. It contained both aluminium and chlorine and had the odor of pyridine. The substance appears to be a single substance, but, up to the present time, no solvent has been found for it. It will be more exhaustively studied in the near future.

\section{Summary.}

As will be seen, from the above general survey, practically all of the organic groups of compounds which have been treated with chloral, chloral hydrate and bromal in the presence of aluminium chloride at low temperatures, have formed distinct condensation products. The treatment of organic compounds with chloral and aluminium chloride at low temperatures, therefore, offers an important means of organic condensation, as some of the compounds prepared and described in this paper cannot be obtained by the Baeyer or sulfuric acid reaction.

No single group of compounds has been exhaustively studied, inasmuch as the important fact to be determined in this preliminary work was, first, whether or not aluminium chloride can be used as a condensation reagent; and second, whether or not it acts catalytically.

The evidence presented in the above experiments, we believe quite sufficient proof that aluminium chloride acts as a catalyst, at the same time, however, playing the part of a simple dehydrating reagent.

${ }^{1}$ Rec. trav. chim., 3I, 369 (I9I2). 
That temperature plays a most important part in this reaction is evident from the results of all the experiments made thus far. In every case it was found that rise in temperature, even but a few degrees above zero, materially changed the reaction and increased the decomposition of both the reacting components. In some cases, as in the ethers, a slight rise above zero not only causes saponification of the ether but also complete decomposition.

In exceptional cases, the chloride seems to act simply as a dehydrating reagent and therefore not as a catalyst in the ordinary use of the term. In most cases, however, it unquestionably plays the part of the catalytic agent, notwithstanding the fact that when equilibrium is finally reached a part of the chloride at least has been converted into the oxide or the hydroxide.

It is evident, from the wide range through which aluminium chloride reacts in the presence of chloral, that the final or complete equilibrium embraces several separate and distinct chemical changes. Some of these are purely catalytic while others apparently are not, although they are entirely dependent upon the catalytic part of the reactions. If we assume, for instance, that aluminium chloride reacts purely as a catalyst, as is evidenceil in some of the above experiments, then the equation would be represented is follows:

$$
6 \mathrm{R} . \mathrm{H}+{ }_{3} \mathrm{CCl}_{3} \mathrm{CHO}+\mathrm{Al}_{2} \mathrm{Cl}_{6}={ }_{3} \mathrm{CCl}_{3} \mathrm{CHR}_{2}+\mathrm{Al}_{2} \mathrm{Cl}_{6}+{ }_{3} \mathrm{H}_{2} \mathrm{O}
$$

This perfectly normal equation, however, by no means excludes other reactions before final equilibrium is reached, for we have not only shown that another reaction takes place before the one indicated above, forming an aluminium alkyl exactly as in the case of Friedel-Crafts reaction, but in a few cases these alkyls were isolated, as will be shown in the second paper now well under way.

From the evidence already presented, a series of reactions may be given as representing the chemical changes which actually take place when equilibrium is finally reached. In the first part of the reaction, aluminium chloride doubtless acts as a pure catalyst as may be indicated by the following equation:

or

$$
\mathrm{C}_{6} \mathrm{H}_{6}+\mathrm{Al}_{2} \mathrm{Cl}_{6}=\mathrm{Al}_{2} \mathrm{Cl}_{5}-\mathrm{C}_{6} \mathrm{H}_{6}+\mathrm{HCl} \text {, }
$$

$$
6 \mathrm{C}_{6} \mathrm{H}_{6}+\mathrm{Al}_{2} \mathrm{Cl}_{6}=\mathrm{Al}_{2}\left(\mathrm{C}_{6} \mathrm{H}_{5}\right)_{6}+6 \mathrm{HCl}
$$

Then through catalytic action of the hydrogen ions of the hydrochloric acid, the second part of the reaction takes place:

$$
\mathrm{Al}_{2}\left(\mathrm{C}_{6} \mathrm{H}_{5}\right)_{6}+{ }_{3} \mathrm{CCl}_{3} \mathrm{CHO}+6 \mathrm{HCl}={ }_{3} \mathrm{CCl}_{3} \mathrm{CH}\left(\mathrm{C}_{6} \mathrm{H}_{5}\right)_{2}+\mathrm{Al}_{2} \mathrm{Cl}_{6}+{ }_{3} \mathrm{H}_{2} \mathrm{O} \text {, }
$$
or

$$
\mathrm{Al}_{2}\left(\mathrm{C}_{6} \mathrm{H}_{5}\right)_{6}+{ }_{3} \mathrm{CCl}_{3} \mathrm{CHO}+6 \mathrm{HCl}={ }_{3} \mathrm{CCl}_{3} \mathrm{CH}\left(\mathrm{C}_{8} \mathrm{H}_{5}\right)_{2}+\mathrm{Al}_{2} \mathrm{O}_{3}+6 \mathrm{HCl}
$$


Eicher or both of these reactions may take place inasmuch as water, hydrochloric acid and, in a few cases, aluminium oxide are liberated.

Detailed work along several lines mentioned above is now under way. So far as the work has progressed, aluminium chloride in each case unquestionably plays the part of a catalyst, whether hydrochloric acid, water, aluminium hydroxide or aluminium oxide is formed during the reaction.

The UNIVERSTY OF MINNESOTA,

MINNEAPOLIS, MINN.

\section{THE ACTION OF TRIOXYMETHYLENE ON THE VARIOUS HYDROCARBONS IN THE PRESENCE OF ALUMINUM CHLORIDE.}

By Geo. B. Franzforthr and V. R. Kozatnur.

Received May 13, 1914.

Ever since Friedel and Crafts discovered the reaction which bears their names, chemists have used it in various ways in order to bring about certain chemical changes, in some cases under entirely different conditions from those recorded by the authors themselves. Thus, Scholl and Seer ${ }^{1}$ showed that anhydrous aluminium chloride, in a few cases, actually breaks off free hydrogen instead of hydrochloric acid. Recently Page ${ }^{2}$ has shown that aluminium chloride possesses the power of transporting chlorine to certain organic compounds. Finally it has been found, under proper physical conditions, to act as a dehydrating agent like concentrated sulfuric acid. It has been shown by Kritchevsky and one of us that when an aldehyde, as chloral, and a hydrocarbon, either benzene or one of its homologs, are brought together in the presence of aluminium chloride at $0^{\circ}$, a reaction analogous to the Baeyer reaction takes place.

In order that the last reaction mentioned might be more thoroughly studied, experiments similar to those mentioned above with benzene and chloral were begun, using trioxymethylene, however, instead of chloral. In each case the same general condensation reaction took place. In a few cases, the reaction seemed to be comparatively simple, while in others it appeared to be extremely complex. This variation seemed to be influenced, largely, by temperature, as a result of the way in which the aluminium chloride was added, either fast or slow, or as to whether the whole mass was kept in a freezing mixture during the reaction. Finally, it was hoped that, in addition to studying the reaction itself, some light might be thrown on the constitution of trioxymethylene.

The molecular structure of trioxymethylene is generally considered to be a ring compound, in which the oxygen and the methylene groups are

I Monatsh., 33, I (1912).

2 Ann., 225, 196 (1884). 